\title{
Scopolamine depresses play fighting: A replication
}

\author{
WILLIAM W. BEATTY \\ North Dakota State University, Fargo, North Dakota
}

\begin{abstract}
The effects of scopolamine and methylscopolamine $(0.125-1.0 \mathrm{mg} / \mathrm{kg})$ on play fighting by juvenile rats were compared. At doses of $0.25 \mathrm{mg} / \mathrm{kg}$ or higher, the centrally active anticholinergic, scopolamine hydrobromide, depressed pinning and reduced the total duration of play fighting. In contrast, scopolamine methylbromide had no effect. Neither drug reliably affected social investigation or rearing.
\end{abstract}

Until recently the psychopharmacology of play behavior among juvenile animals has received little experimental attention. Within the past 5 years, the effects of opiates (Beatty \& Costello, 1982; Panksepp, Herman, Vilberg, Bishop, \& De Eskinazi, 1980), psychomotor stimulants (Beatty, Dodge, Dodge, White, \& Panksepp, 1982), and anticholinergics (Thor \& Holloway, 1983) have been described. The present paper describes a systematic replication of the recent report (Thor \& Holloway, 1983) that scopolamine suppresses play fighting in juvenile rats by its central action.

\section{METHOD}

\section{Animals}

The subjects were 18 male albino rats of a Sprague-Dawleyderived strain bred by the Holtzman Company, Madison, Wisconsin, and shipped to the laboratory at 21 days of age. Except during behavioral testing, they were caged singly in standard laboratory cages and were given free access to food and water. The cages were housed in an air-conditioned animal room that was illuminated from 0700 to $1900 \mathrm{~h}$. Behavioral tests occurred between 1400 and $1600 \mathrm{~h}$.

\section{Apparatus \\ The test chamber, a $51 \times 32 \times 47 \mathrm{~cm}$ high box made of plywood painted black and having a clear plastic front, was housed in a quiet room. The chamber was illuminated by two $60-\mathrm{W}$ red incandescent light bulbs mounted in desk lamps $68 \mathrm{~cm}$ above the floor of the chamber. This arrangement pro- vided the minimum light necessary to obtain clear videotape recordings.}

\section{Procedure}

At 24 days of age, the rats were assigned randomly to test pairs; they then were habituated to the apparatus in pairs for $10 \mathrm{~min}$ each day for 3 days. Once formed, pairs remained intact for the duration of the study. Starting on Day 27 and continuing for 9 consecutive days, each pair was given a 10 -minlong test $20 \mathrm{~min}$ after an ip injection of $0.125,0.25,0.5$, or $1.0 \mathrm{mg} / \mathrm{kg}$ of scopolamine hydrobromide (Smith Kline) or methylscopolamine (scopolamine methylbromide, Sigma) or an

This research was supported in part by NSF Grant BNS 8201448. Kevin Costello scored the videotapes. The author's mailing address is: Department of Psychology, North Dakota State University, Fargo, North Dakota 58105. injection of the saline vehicle. Doses are expressed as the weight of the salt, and all treatments were given in a volume of $1 \mathrm{ml} / \mathrm{kg}$. Both members of the test pair received the same drug treatment. The order of treatments was counterbalanced according to a Latin square design.

All sessions were videotaped, and they were subsequently scored by a rater who was blind to the drug treatment received by the rats. The following behaviors were scored for each pair: pinning frequency (one rat rolls the other onto its dorsal surface and stands over it), rearing frequency (either rat raises its forepaws at least $1 \mathrm{~cm}$ off the floor), frequency and total duration of play fighting, and frequency and total duration of social investigation. Play fighting was a composite of several behaviors including tail pulling, pouncing, boxing, wrestling, pinning, and chasing. Although the latter behavior is often considered separately (Aldis, 1975), our previous research (e.g., Beatty et al., 1982) has consistently shown that, under the present conditions, the frequency, duration, and temporal patterning of chasing are highly and positively correlated with other measures of play fighting. A typical play bout begins when one rat pounces on the other, which generally leads to mutual wrestling or (occasionally) chasing or (rarely) boxing. Wrestling matches often lead to pins, which might be followed by a brief cessation in social interaction or a reversal as the pinned animal scrambles to its feet and chases or wrestles with its partner. Timing of the actual individual play bouts continued until a clear interruption in the ongoing sequence of play fighting was detected. Bouts of social investigation, which mainly consisted of anogenital sniffing but also included social grooming, were timed in a similar manner.

\section{Data Analysis}

For each dependent measure, separate repeated-measure ANOVAs were performed to evaluate the overall effects of scopolamine and methylscopolamine. Each analysis included the saline control condition as one dosage level. Subsequent pairwise analyses were performed if the omnibus analysis revealed an overall effect of drug treatment. In addition, direct comparisons of the effects of scopolamine and methylscopolamine were made for those doses of scopolamine that reliably altered performance relative to the saline control condition.

\section{RESULTS}

Table 1 summarizes performance on all measures. There it can be seen that scopolamine depressed play fighting regardless of whether the number of pins, the frequency of play bouts, or the total duration of play fighting was used to index the behavior $\left[F_{s}(4,32)>\right.$ 
Table 1

Mean Social Behavior and Rearing Per Pair

\begin{tabular}{|c|c|c|c|c|c|c|c|c|c|}
\hline & \multicolumn{4}{|c|}{ Methylscopolamine $(\mathrm{mg} / \mathrm{kg})$} & \multirow{2}{*}{$\begin{array}{c}\text { Saline } \\
0\end{array}$} & \multicolumn{4}{|c|}{ Scopolamine $(\mathrm{mg} / \mathrm{kg})$} \\
\hline & 0.125 & 0.25 & 0.5 & 1.0 & & 0.125 & 0.25 & 0.5 & 1.0 \\
\hline Pins & 36.9 & 43.9 & 41.8 & 32.3 & 44.9 & 27.8 & 9.8 & 11.4 & 0.4 \\
\hline Rears & 37.4 & 41.2 & 45.5 & 49.2 & 50.7 & 52.6 & 41.7 & 42.1 & 67.0 \\
\hline \multicolumn{10}{|l|}{ Play Fighting } \\
\hline Bout Frequency & 47.0 & 54.9 & 46.4 & 41.1 & 47.6 & 37.9 & 19.4 & 16.9 & 1.7 \\
\hline Total Duration & 123.0 & 138.6 & 119.5 & 106.2 & 128.9 & 102.0 & 49.3 & 42.6 & 4.4 \\
\hline \multicolumn{10}{|l|}{ Social Investigation } \\
\hline $\begin{array}{l}\text { Bout Frequency } \\
\text { Total Duration }\end{array}$ & $\begin{array}{l}10.1 \\
16.5\end{array}$ & $\begin{array}{r}7.9 \\
11.4\end{array}$ & $\begin{array}{r}8.6 \\
14.1\end{array}$ & $\begin{array}{r}8.3 \\
14.3\end{array}$ & $\begin{array}{r}7.3 \\
12.0\end{array}$ & $\begin{array}{r}7.2 \\
12.8\end{array}$ & $\begin{array}{l}13.6 \\
25.4\end{array}$ & $\begin{array}{l}10.1 \\
20.1\end{array}$ & $\begin{array}{r}7.6 \\
12.8\end{array}$ \\
\hline
\end{tabular}

Note-Total duration given in seconds.

$8.80, \mathrm{p}<.001]$. Subsequent analyses showed that, relative to the saline control, doses of $0.25 \mathrm{mg} / \mathrm{kg}$ or greater reduced play fighting on each of these measures $[\mathrm{Fs}(1,8)>9.54, \mathrm{p}<.02]$. The lowest dose $(0.125 \mathrm{mg} / \mathrm{kg})$ did not reliably affect any measure of play fighting.

In contrast, methylscopolamine, which does not cross the blood-brain barrier, did not significantly change play fighting on any measure (all Fs $<1.88$ ). Furthermore, the frequencies of pinning and play bouts, as well as the total duration of play fighting, were reliably greater after methylscopolamine $(0.25-1 \mathrm{mg} / \mathrm{kg})$ treatment than following a comparable dose of scopolamine $[\mathrm{Fs}(1,8)>7.80, \mathrm{p}<.03]$.

Both the frequency of social investigation bouts and the total duration of this form of social activity were somewhat higher after scopolamine treatment, but this effect was not reliable $(\mathrm{Fs}<2.39)$. Neither scopolamine nor methylscopolamine affected rearing ( Fs $<2.04)$.

\section{DISCUSSION}

Thor and Holloway (1983) found that play fighting was inhibited by scopolamine in doses of $0.3 \mathrm{mg} / \mathrm{kg}$ or greater but that a much higher dose $(3 \mathrm{mg} / \mathrm{kg})$ of methylscopolamine was ineffective. The present findings are in very good agreement with Thor and Holloways's results, and, taken together, they indicate that the central, rather than the peripheral, anticholinergic actions of the drug are responsible for its effects on play fighting.

Thor and Holloway (1983) also found that scopolamine increased social investigation but that methylscopolamine did not have this effect. They suggested that scopolamine might inhibit play fighting by activating a competing response, specifically, social investigation. While we did not observe a reliable effect of scopolamine on social investigation, there was a nonsignificant increase in both frequency and duration at the intermediate doses of the drug. However, the amount of time our rats spent in social investigation was so small that it is doubtful that changes of the magnitude we observed could account for much of the drug's influence on play fighting. Hence, the sup- pression of play fighting by scopolamine is likely to involve more than the simple activation of an alternative form of social behavior.

Likewise, the effects of scopolamine on play fighting are probably not simply secondary to drug-induced increases in locomotor activity or investigatory behavior. We found no effect of scopolamine on rearing, which is not surprising considering the age of our subjects. Bauer (1982) found no evidence of effects of scopolamine on rearing until rats were 36 days of age. furthermore, the effects of scopolamine on rearing are complexly influenced by apparatus size and familiarity (Hughes, 1982), and decreases, as well as increases, in rearing commonly have been observed.

Stimulation of locomotor activity is a more consistent effect of scopolamine (Hughes, 1982) that has been observed in young rats (Bauer, 1982; Thor \& Holloway, 1983). But since play fighting can be suppressed by doses of scopolamine that do not stimulate activity (Thor \& Holloway), the effects of the drug on play are not simply secondary to its influence on activity.

\section{REFERENCES}

Aldis, O. Play fighting. New York: Academic Press, 1975.

Bauer, R. H. Age-dependent effects of scopolamine on avoidance, locomotor activity and rearing. Behavioural Brain Research, 1982, 5, 261-279.

Beatty, W. W., \& Costello, K. C. Naloxone and play fighting in juvenile rats. Pharmacology, Biochemistry and Behavior, 1982, 17, 905-907.

BeatTy, W. W., Dodge, A. M., Dodge, L. J., White, K., \& PANKSE PP, J. Psychomotor stimulants, social deprivation and play in juvenile rats. Pharmacology, Biochemistry and Behavior, $1982,16,417-422$.

Hughes, R. N. A review of atropinic drug effects on exploratory choice behavior in laboratory rodents. Behavioral and Neural Biology, 1982, 34, 5-41.

Panksepp, J., Herman, B. H., Vilberg, T., Bishop, P., \& De Eskinazi, F. G. Endogenous opioids and social behavior. Neuroscience Biobehavioral Reviews, 1980, 4, 473-487.

ThoR, D. H., \& Holloway, W. R., JR. Scopolamine blocks play fighting behavior in juvenile rats. Physiology \& Behavior, $1983,30,545-549$.

(Manuscript received for publication June 8, 1983.) 